\title{
Differentiated Thyroid Gland Carcinoma by AJCC v8 Stage
}

National Cancer Institute

\section{Source}

National Cancer Institute. Differentiated Thyroid Gland Carcinoma by A/CC v8 Stage. NCI

Thesaurus. Code C140965.

A term that refers to the staging of differentiated thyroid gland carcinoma, following the rules of the TNM AJCC V8 classification system. 